\title{
Aproximaciones a la experiencia estética de la cueca chilena: la fiesta como perspectiva estética y filosófica
}

\author{
Approximations on the Aesthetic Experience of the Chilean \\ Cueca: Festival as an Aesthetic and Philosophical Perspective \\ Aproximações à experiência estética da cueca chilena: a festa \\ como perspectiva estética e filosófica
}

Gabriel Andrés Sepúlveda Rodríguez*

\section{RESUMEN}

En este artículo se aborda el fenómeno de la cueca chilena, específicamente su vertiente urbana, como experiencia estética, desde los elementos que residen en ella: la lírica popular, el baile y el canto englobados en la expresión de la farra o fiesta. Para ello, se revisará la pertinencia de este estudio dentro de la filosofía, con sus roces con otras disciplinas y los propios límites del lenguaje filosófico para abordarla. Desde el trabajo del filósofo chileno Fidel Sepúlveda y de Hans-Georg Gadamer, estudiaremos sus componentes formales para observar el fenómeno en su dimensión estética. El artículo culmina proponiendo una mirada distinta para abordar esta experiencia estética a partir del ambiente, como una nueva perspectiva para emprender un estudio estético y filosófico.

\section{ABSTRACT}

This article addresses the phenomenon of Chilean cueca, specifically its urban style, as an aesthetic experience, from the elements that lie within it: popular lyric, dance and song, encompassed in the expression of party or festivity. To do so, the pertinence of this study will be reviewed from within philosophy, in its ties to other
Palabras clave: cueca chilena, experiencia estética, fiesta, ambiente, roto chileno.

Keywords: Chilean cueca, aesthetic experience, festival, atmosphere, roto chileno.

\footnotetext{
* Chileno, estudiante de Pedagogía en Filosofía de la Universidad Católica Raúl Silva Henríquez, Chile. Contacto: gasepulveda@miucsh.cl.

ORCID: https://orcid.org/0000-0002-5058-5153
} 
disciplines and the limits of philosophical language to address it. Based on the work of Chilean philosopher Fidel Sepulveda and Hans-Georg Gadamer, we will study its formal components to observe the phenomenon in its aesthetic dimension. The article culminates by proposing a different view to address this aesthetic experience, based on atmosphere, as a new perspective for carrying out an aesthetic and philosophical study.

\section{RESUMO}

Neste artigo é abordado o fenômeno da cueca chilena, especiPalavras-chave: ficamente sua vertente urbana, como experiência estética, desde os elementos que nela residem: a lírica popular, a dança e o canto englobados na expressão da farra ou festa. Para isso, será revisada a pertinência deste estudo dentro da filosofia, com suas confrontações com outras disciplinas e os próprios limites da lincueca chilena, experiência estética, festa, ambiente, roto chileno. guagem filosófica para abordá-la. Desde o trabalho do filósofo chileno Fidel Sepúlveda e de Hans-Georg Gadamer, estudaremos seus componentes formais para observar o fenômeno em sua dimensão estética. $\mathrm{O}$ artigo finaliza propondo um olhar distinto para abordar esta experiência estética a partir do ambiente, como uma nova perspectiva para empreender um estudo estético e filosófico. 


\section{La cueca como experiencia estética}

Siendo parte del campo de la estética, como experiencia que involucra la sensibilidad y la emocionalidad, la cueca chilena sume a los espectadores en la obra desde su sensibilidad, que se ve afectada, diluyendo las barreras propias de la subjetividad. Esto permite conformar una relación momentánea entre la obra y el sujeto que la aborda, poniéndolo en movimiento y en interacción con ella.

Producir este encuentro, desde la estética, entre la cueca chilena y la filosofía, bordea y juega con las capacidades del lenguaje en general y filosófico en particular, porque, como dice la tradición, "la cueca no puede hablarse en buen castellano". Por ello, esta exposición deberá rondar por los campos de la historia, la sociología y la estética, a través textos de Fidel Sepúlveda sobre la estética del folclor. Este autor logra construir una aproximación al modo en que el arte pasa a ser parte de la vida, retomando aspectos de la obra de Has-Georg Gadamer, como el juego y la fiesta.

El diálogo se producirá entonces entre estos textos y la obra recopilada sobre la cueca chilena, principalmente las cuecas llamadas "del folclor", y el trabajo de autores que han cultivado la tradición cuequera entregada por "Los Chileneros" ${ }^{1}$ a las nuevas generaciones de cantores, la tradición oral y elementos de trabajos sobre la historia y la expresión de la cueca chilena. Del mismo modo, se buscará establecer una reivindicación de la pluralidad presente en este tipo de obras, lo que permitirá construir una apreciación estética ajena a la obra de los autores reconocidos, apoyándose en el conjunto de la sociedad que construye una obra común: el folclor.

Con lo anterior, mostraremos cómo las expresiones artísticas contenidas en la cueca se conjugan con los elementos de su contexto, para producir una experiencia estética sin sujetos ni objetos determinados, sino que establecida como un ambiente: la farra, la fiesta chilena que logra aunar baile, canto y lírica, sin apartarlos de la vida de sus integrantes.

\footnotetext{
1 Se nombra a este conjunto como referencia a algunos de los cultores de la cueca chilena, y se invita al lector escuchar a otros como Los Chinganeros, Los Paleteados del Puerto y La Isla de la Fantasía.
} 
En adelante, más que esforzarnos por establecer un canon de belleza o los parámetros de un análisis subjetivo, nos esforzaremos por observar y relacionar los elementos que conforman la experiencia estética de la cueca chilena, dejando abierta la invitación a encontrarse con ella.

\section{La cueca chilena, aspectos formales}

En la práctica humana del canto, de la lírica popular y del baile, se puede encontrar formas primitivas de arte, que parecen nacer de la espiritualidad inmanente al humano en un intento de conexión con lo trascendente. Así, en la mayoría de los espacios sociales, se observan fórmulas en las que estos tres elementos se conjugan y constituyen una experiencia estética, que involucra al espectador con las fuerzas que surgen desde la expresión de la humanidad en el arte, y se hace presente en los espacios que el humano habita.

La cueca, en sus variadas formas, es expresión de la tradición popular que nace del mestizaje, por lo que es posible encontrarla en diversos países a lo largo de Latinoamérica, con formas más consistentes en Argentina, Bolivia y Chile. En estos países, la cueca sostiene una estructura coreográfica y métrica similar ${ }^{2}$, que consiste en una vuelta inicial, una medialuna, una segunda vuelta, el escobillado, una tercera vuelta, el zapateo y la vuelta final ${ }^{3}$.

Su métrica está compuesta de coplas y seguidillas (siguiriyas). Específicamente, la cueca chilena está formada por una copla, es decir, cuatro versos octosilábicos de rima consonante del segundo con el cuarto; una seguidilla, esto es, cuatro versos, dos de ellos de siete sílabas y dos de cinco, correspondiendo los de cinco sílabas a los versos segundo y cuarto que deben rimar de forma consonante; una segunda seguidilla, de la misma forma que la anterior, pero que debe empezar con el último verso de la seguidilla anterior, con la muletilla "ay sí" (o "sí", o "mi alma"); y, por último, el remate, que consiste en media seguidilla (o pareado), esto es, un verso de siete y otro de cinco sílabas,

Resaltamos la importancia del adjetivo "similar", pues en estos países se acostumbra a interpretarla de forma distinta a como se hace en Chile.

No entraremos en más detalles en el aspecto coreográfico, debido a que esta problematización sería propia de otro estudio. 
que deben rimar de forma consonante entre sí, con variantes como una media copla. Musicalmente, su ritmo está en compás de tres cuartos (3/4) o de seis octavos (6/8), formando cuarenta y dos compases. En cuanto a su canto, se le agregan reiteraciones de algunos versos ${ }^{4} \mathrm{y}$, también, frecuentemente, muletillas que pueden ser frases, onomatopeyas o palabras sueltas, aunque las más comunes son caramba, negra del alma, sí ayayay o la repetición de una parte del verso que precede o antecede, generalmente de tres sílabas (Torres, 2008, pág. 14). De esta manera, la cueca es en su poesía de la siguiente forma:

Salgo al campo a divertirme

a ver si olvidarte puedo

me ha salido lo contrario

cada día más te quiero

Al campo de las flores

salgo a pasearme

salieron tus ojitos

a cautivarme

A cautivarme, sí

que ojos tan bellos

que se van y me dejan

muerta por ellos

Muero por tus ojitos

Tan re bonitos (Torres 285)

$\mathrm{Al}$ cantarla pasa a la forma:

Salgo al campo a divertirme

a ver si olvidarte puedo, ayayay

a ver si olvidarte puedo, ayayay

me ha salido lo contrario

cada día más te quiero, ayayay.

Salgo al campo a divertirme

Al campo de las flores

salgo a pasearme

$4 \quad$ Se repite el primero al final de la copla, el segundo inmediatamente y los versos quinto y sexto se repiten al final de la primera seguidilla. 
salieron tus ojitos

a cautivarme, ayayay

Al campo de las flores

salgo a pasearme.

A cautivarme, sí

que ojos tan bellos

que se van y me dejan

muerta por ellos, ayayay.

Muero por tus ojitos

Tan re bonitos (Torres 2008).

Dentro de las expresiones de la cueca, es importante resaltar la importancia de su diversidad en relación con su ubicación geográfica. Esto implica que podemos encontrar variaciones, como la cueca campesina, que agrega compases hasta sumar cincuenta y dos, como también variantes contundentes en su sonoridad, agregando bombos de cuero en Chiloé, instrumentos de viento en el norte, lo que la adapta la sonoridad a la identidad propia del lugar de donde proviene cada "estilo" de cueca. Sin embargo, los cultores insisten en llamarla por el nombre la chilena $a^{5}$, a modo de no hacer distinción entre sus variadas expresiones, sin tomar en cuenta sus diferencias.

Luego de haber introducido y explicado la cueca en un marco general, que es complejo, pues confluyen en él aspectos de variadas disciplinas, es propicio retomar la idea de la situación geográfica para acercarnos al estudio que nos compete. La cueca a la que nos referiremos en este trabajo al hablar de cueca es la chilena, en su expresión como cueca brava: aquella interpretada por los cantores en la zona central de Chile.

Haremos hincapié también en la interpretada en Santiago y Valparaíso, que nace en las calles y fiestas del pueblo, siendo llevada, por primera vez, a la discografía, a modo de conjunto, por Los Chileneros ${ }^{6}$.

5 Este nombre nace, según Vicuña Mackenna, como apodo a la zamacueca por los oficiales de la Restauración en Perú, luego de la caída de la confederación Perú-boliviana en 1939 (Garrido 36).

${ }_{6} \quad$ El portal Música Popular (s.f.) nos ofrece una breve biografía: Conjunto integrado por Hernán Raúl “Nano" Núñez Oyarce, criado en Estación Central, que en sus variados oficios reconoce haber sido lustrabotas; Luis Hernán "Baucha” Araneda Oyarzún, también de Estación Central que además de cantor era matarife del Matadero Blanqueado de Quinta 
Es importante reconocer que ellos no fueron los primeros en interpretar esta forma de cueca, sino que son portadores de una tradición ya instalada en los comercios, conventillos, fiestas y burdeles de su época, y que gracias a su trabajo y al de muchos cultores, hoy podemos decir que esta tradición persiste.

Antes de avanzar, es pertinente hacer un alcance histórico, el 18 de septiembre de 1979 fue promulgado el decreto de ley número veintitrés (23), durante la dictadura militar de Augusto Pinochet, que declara a la cueca danza nacional de Chile, y donde se promueve su cultivo (Biblioteca del Congreso Nacional). A partir de aquí, a nuestro juicio, se instaura una forma unificada de la expresión estilística de la cueca, encasillada en la cultura del huaso y determinada por la imagen del hacendado, el patrón de fundo. Esta homogeneidad está alejada de las características propias de la expresión de la chilena.

La cueca que aquí exponemos no es la estatal, sino la nacional. Además, bajo nuestra percepción, hablar de danza puede no captar esta expresión en sus posibilidades, pues, si bien hay una estructura determinada, se "baila como salga", porque al bailarse lo que aparece ante la vista es la muestra de lo que los bailarines están sintiendo como expresión de su sensibilidad. Es imposible encasillarla en un parámetro claro, como lo dispone una conceptualización de la danza.

Los Chileneros y otros grupos, como ya mencionamos, interpretaron una cueca distinta, con innovaciones en su sonoridad:

Menor utilización del arpa y mayor presencia del piano (dejando a la guitarra un rol de acompañamiento), mayor presencia del tañador (sin uso del tormento), uso frecuente de más de un pandero, mayor presencia del contrabajo como base de conducción de la armonía y presencia irregular de batería.

Normal; Raúl René “Perico" Lizama Quintero, nacido en Valparaíso e hijo de cantores, por tanto, cantor, además de multi-instrumentista, que no aprendió nunca a leer ni a escribir; Eduardo "el chico" Mesías, comerciante y cantor del que no se conoce mucho de su vida; y por Carlos Roberto "Pollito" Navarro Espinoza, Nacido en el sector de El Salto, cercano a la Vega Central, en Recoleta, que debido a los bajos ingresos económicos de su familia dejó el colegio para dedicarse a cantar en fondas, fiestas, quintas de recreo y burdeles; ellos no eran precisamente artistas profesionales, sino que cantores populares, o de oficio que se dedicaban a la cueca no como actividad económica, sino que social. 
Nuevo uso de la voz: utilización del estilo "gritado" con gorgoreo, tonos agudos o brillantes, alternancia de voces y, en algunas ocasiones, performance vocal en formato de rueda circular o semicircular. Todos estos aspectos forman parte del canto a la rueda; voces exclusivamente masculinas (género).

Utilización de mayor velocidad en el pulso (con voces en terceras paralelas).

Diversificación de las temáticas de las cuecas: mayor presencia de temas ligados a las historias y oficios de sujetos populares (prostitutas, mineros, matarifes, carpinteros, vendedores, vagabundos o "pungas", presos, boxeadores, delincuentes) incluyendo temáticas de orden social como la historia del país, los espacios urbanos de Santiago y Valparaíso y la importancia de la mujer.

Aspectos performativos: mayor tendencia al carácter silábico del canto (una sílaba para cada nota) y uso de un vestuario informal o semi-formal descartando trajes folclóricos típicos de huaso o china (Espinosa 201)

Todas estas características conforman el estilo propio de un sector popular, más arraigado a las chinganas y a la fiesta que a las formas de celebración de la alta sociedad, recogiendo aspectos culturales en su performatividad; por ejemplo, el canto gritado es propio de las melodías con las que se anuncian los productos a la venta.

Un punto que no hemos tratado aún es el canto particular que tiene esta cueca: el canto por mano estructurado en el canto a la rueda o a la daira, en el que cuatro cantores de un lote ${ }^{7}$, generalmente más grande, se alternan en el canto, de forma que cada uno interpreta una de las partes de la cueca (de su estructura poética). Este es para muchos el aspecto más importante de esta variante de la cueca, lo que retomaremos más adelante.

\section{Componentes de la experiencia estética de la chilena}

En este punto, nos alejaremos de las discografías para acercarnos a la expresión social y popular de la chilena, y pensaremos en un ambiente

Grupo de cantores y músicos. 
de fiesta y jolgorio, con olor a carne asada, vasos de vino, manteles de plástico, baile y canto, en donde la pista de baile ya no es pista, sino que es cancha, donde se juega el todo y donde emerge lo espiritual. En esta construcción nos propondremos reconocer que la cueca chilena, en tanto expresión de tradición popular, es una experiencia estética, que logra adentrarse en la confluencia del entorno habitado a través de la expresión del canto, el baile y la poesía, que construyen un ambiente donde es posible que se develen los sujetos en una individualidad compartida.

Si bien lo que prosigue es identificar los elementos estéticos de la cueca, es menester reconocer primero si esta expresión puede ser, académicamente hablando, una experiencia estética. La Enciclopedia Herder indica que las experiencias estéticas provienen de los sentimientos estéticos, las sensaciones de agrado que produce la contemplación de un objeto bello, del goce o del grado producido por la percepción de lo bello. La pregunta, ahora, recae en indagar si es pertinente realizar un estudio estético de una expresión folclórica.

Fidel Sepúlveda reconoce que la historia de la estética ha desechado, en gran parte, el estudio de las tradiciones, ocupándose del "arte de autor conocido, (...) del arte que se conoce y se valora como tal" (69). Critica el autor la tecnicidad con la que esta disciplina se ha alejado de la sensibilidad frente a lo bello, reduciendo su estudio, por ejemplo, a la relación de las intenciones del autor con la obra expuesta. Indica, incluso, que no hay grandes estudios respecto a lo que él denomina la "alteridad tradicional".

El folclore, en su alteridad, constituye un entramado que es expresión del estar del hombre en su entorno, en tanto él lo interpreta de manera simbólica, y es esto lo que, para el autor, lo hace propio de un estudio estético. Así, podemos reconocer a la cueca como una forma de arte —-más allá de sus estructuras y variantes - y a los cuequeros y cuequeras - sus intérpretes-como artistas:

El arte inventa, crea formas capaces de contener maneras universales de sentir, de pensar, de ser. El artista es alguien capaz de inventar estructuras que, desde su morfología, sugieren a los sentidos y a la inteligencia realidades inherentes a la especie (...). El arte le dicta a la humanidad su código de vida, la verdad de su verdad, la mentira 
de su mentira. El Arte es vida. No puede ser de otra manera porque se hace desde lo más alto del espíritu del hombre. (Sepúlveda 2015)

Con esto, se comprende la construcción de este universo complejo, que conserva y cultiva la memoria de un pasado perseguido, como lo presentan quienes se dedican hoy a cantarla ${ }^{8}$. Ella cobra un carácter como código de vida y establece una relación con su intérprete que no permite la indiferencia frente a las temáticas que aborda.

El contenido de su poesía está colmado de tópicos que el cantor puede experimentar en su cotidiano, ella se encarna en su posibilidad cotidiana; el que pega el grito logra, en su canto, actualizar el pasado, haciéndolo presente en un ambiente que brilla por su efervescencia, la misma que tuvieron aquellos taitas $^{9}$ estableciendo una diacronía entre el verso escrito en el pasado, o que refiere a él, y el presente.

El valor de este arte fue expresado por Luis Castillo en una décima:

Como no hemos de cantarte

hermosa cueca chilena

si eres la dulzura plena

que nos hace venerarte

por eso hemos de cuidarte

como la más fina joya

porque eres nuestra gloria

hermosa niña morena

cómo te amamos chilena

bendición de nuestra historia (Tricolores)

Se manifiesta, así, el sentir de devoción de muchos cuequeros y cuequeras que aprecian la posibilidad de ligarse a su pasado a través de este arte, que poco a poco revela en el artista una conexión histórica, permitiéndole identificarse con aquel sentir de antaño. Catalogar a la chilena como la "hermosa niña morena", nos ayudará a aproximarnos a la forma en la que se cultiva este arte con cuidado y minuciosidad en los detalles, siendo importante, por ejemplo, ver qué forma tiene la

$8 \quad$ Para comprender esto es necesario recordar lo ya dicho sobre el decreto de la cueca como danza nacional. En otros momentos de la historia, también fue prohibida por Bernardo O'higgins, debido a que alborotaba al pueblo.

9 Taitas: viejos cantores. 
chapa del pandero que se va a ocupar, pues todo en ella cobra sentido en el mensaje que intenta entregar, ya que estos detalles son fruto del camino recorrido por la chilena.

Raúl Núñez llegó a decir que "el roto buscaba cualquier cuestión, podía estar a la orilla de un camión, agarraba los tapabarros, lo que sonaba mejor y se ponía a tañar" (Rojas, 1998). Estas sonoridades y formas de interpretar la cueca se acoplaron a ella, sin ser contradictorias frente al cuidado por el detalle. De a poco, estos elementos consolidaron un rostro más parecido al de los barrios menos acomodados de las urbes. Este cuidado tiene afecciones en la vida de quien la cultiva, consideremos que "el arte, además puede introyectarse en la vida, puede devenir el arte de la vida. Vivir la vida es un verdadero arte o debiera serlo" (Sepúlveda, 2015, pág. 35). Y es que el buen roto cuequero debe hacerse a los instrumentos hasta dominarlos, buscar la forma de hacer que su voz no le falle en largas horas de fiesta, y buscar también la chilena allí donde ella esté, ya sea en lo escondido o en lo marginal.

Así, la chilena pasa a ser la "hermosa niña morena", que el roto ama y que cuida como a su propia hija, lo que permite comprender el respeto y cuidado de esta expresión. Esto muestra cómo en este verso se esconde la razón de la supervivencia de la cueca en lo marginal, pues tiene la mirada cautivadora de la fiesta, que embriaga a quienes se atreven a entrar en ella.

En la marginalidad se construyó la tradición chilenera, en un entorno de poco espacio, suciedad, hacinamiento, trabajo duro y exuberancia de todo aquello que las buenas costumbres rechazan, generando códigos propios que, en principio, son réplica de la cultura de la que proviene. De aquí se desprenden versos que nos sitúan en un espacio determinado, haciendo florecer imaginarios "Estando en Viña del Mar / tomando con mis amigos" (Torres 319), que de imaginario tienen lo que de realidad, trayendo a la mente las imágenes de la bohemia que no admite sobriedad ni pulcritud, sino despilfarro y exuberancia. Aparecen las costumbres aferradas a aquellos rotos a pata pelá ${ }^{10}$ que habitaban esos espacios:

10 Los matarifes del Matadero de Franklin trabajaban descalzos para no ensuciar los fluidos que desprendía la faena de los animales, utilizados para otros subproductos (Castro 2011). 
en un carro de Viña

viene un huasito

yo le vengo afanando

el relojito ${ }^{11}$ (Torres 222)

Se expresa así la disposición ética del roto, que se aleja del estándar de una sociedad ilustrada, y que pareciera acercarse a la supervivencia en el entorno donde habita forzosamente. Y, como en todo ambiente hostil, es necesario el trabajo. Así reza el verso:

Despierta, pues, cuadrinito ${ }^{12}$

que es hora de madrugar

ya tocaron las campanas

y es preciso trabajar (Torres, 2008, pág. 222).

Su vida nunca ha sido acomodada, siempre ha debido ser vivo para el trabajo, para ganar lo suficiente para el día y poder sustentarse. Como el objetivo era hacerse el día $a^{13}$, se le conoció por astuto: "engañan a las viejas / con las mollejas" ${ }^{14}$ (Torres, 2008, pág. 222), verso que deja entrever que, por hacerse el día, el roto está dispuesto al engaño y el robo. Los versos anteriores muestran situaciones que constituyen el imaginario o, más bien, la identidad y memoria del roto. También hacen patente la crudeza de la lírica de la cueca, hay pocas metáforas y es frecuente el uso de un lenguaje seco y rudo; sus palabras son mucho más cercanas al habla coloquial de sus intérpretes que en otros estilos de su época ${ }^{15}$.

El espacio al que se refiere esta lírica popular circunda entre Valparaíso y Viña del Mar, el campo chileno del Valle Central ${ }^{16}$, el Matadero, la Estación y la Vega, lugares de comercio, pequeños bares, casas de remolienda que pasan a ser las canchas en donde se jugaba la vida. Entender este "jugarse la vida" nos posibilita abrir el movimiento de los

\footnotetext{
11 Ambos fragmentos de la cueca "Viña del Mar", recopilada por Los Chileneros.

12 Diminutivo de cuadrino, matarife o jifero, que era el encargado de matar al animal y hacer los cortes de la carne o desposte.

13 Ganar el dinero suficiente para sobrevivir el día.

14 Ambos fragmentos de la cueca Los Matarifes (o Levántate cuadrinito), recopilada por el conjunto Los Centrinos del Matadero.

15 Boleros, tangos, valses peruanos.

16 En especial, aquellas de la tradición llevadas a las urbes antes de las migraciones campo-ciudad.
} 
sujetos dentro de la chilena a partir del juego. Gadamer (1999) propone que el juego surge como movimiento o vaivén de los elementos que lo componen, sin estar atados a ningún objeto ulterior, de la misma forma que no es necesario que haya un sujeto estático que se comporte como jugador para que surja el juego ${ }^{17}$, sino que, en último término, es el juego el que se juega (146). En este ámbito se nos presenta el modo de ser del arte y, en consecuencia, de las experiencias estéticas. Asimismo se nos presenta la chilena, como diluyente de las limitaciones propias de las estructuras de sujetos, desenvolviéndose hacia la construcción conjunta de la obra que se crea, en la cual los participantes de esta representación asumen su estar en ella, tal como participantes de un juego.

El juego surge en el movimiento lúdico, y quienes lo juegan lo experimentan como una actividad sin esfuerzo en la cual abandonarse, haciendo aparecer el cierre y la vuelta empezar que trae consigo el impulso de seguir jugando (Gadamer 1999 148). Del mismo modo, la cueca cantada a la rueda propone constantemente la vuelta a empezar, se interpretan una tras otra durante horas, sin esfuerzo, o al menos sin percepción de él, gracias al ambiente de fiesta en el que se envuelven los sujetos.

Quizá sea pertinente enmarcarnos en un bar como el esbozado por Giannini (88-94), donde se detiene el tiempo que se percibe comúnmente y se construyen núcleos confesionales. El bar establece un espacio en el que se produce un aislamiento del cotidiano, capaz de conectar al individuo con su interioridad, en la búsqueda por encontrar una forma de escapar de su vida por un momento o, como diría el autor, de transgredir lo cotidiano.

El espacio físico delimitado por el bar permite impregnar la experiencia estética de una imagen particular, que aparenta estar desenfocada, mezclando y difuminando colores, olores, sabores, sonidos; alte-

\footnotetext{
17 "El término alemán correspondiente, das Spiel, posee una serie compleja de asociaciones semánticas que no tienen correlato en español, que hace difícil seguir el razonamiento que se plantea en los capítulos siguientes. La principal de estas asociaciones es la que lo une al mundo del teatro: una pieza teatral también es un Spiel, juego; los actores son Spieler, jugadores; la obra no se «interpreta», sino que se «juega»: es wird gespielt. De este modo, el alemán sugiere inmediatamente la asociación entre las ideas de «juego» y «representación», ajena al español (N. del T.)" (Gadamer 1999 143).
} 
rando la percepción en su totalidad, con la ayuda de ruidos estridentes y alcohol, que poco a poco liberan al hombre y lo invitan a la cancha, lo hacen más valiente, como dice la invitación popular a bailar " $a$ la cancha los valientes". Los bares que conservan la cultura de la chilena poseen una composición particular en la que prima el desorden, pues intentan quedarse atrapados en el tiempo, con objetos, tragos e imágenes de antaño, recargando las paredes, como huyendo del momento histórico presente y atrayendo al recuerdo lo que fue el Chile de antes.

Es prudente añadir el factor "espacio físico" a la experiencia estética de la chilena, porque, precisamente, deja de serlo para convertirse en núcleos sociales y culturales, transformados de espacios inertes a vitales por medio de la música y el movimiento de los sujetos que, a su vez, comparten una experiencia que es estética en cuanto involucra su sensibilidad.

La chilena se vuelve confesión en el baile, porque quien realiza este ejercicio logra el vaciamiento de lo que trae desde la calle. Al aplaudir y cruzar las miradas, logra encarar a su pareja y demostrar las intenciones que llevará durante los cuarenta y dos compases; se deja llevar por la música y se entrega a lo que su corazón, unido al pulso de los bajos, le dice que haga. De esta forma, ninguna chilena que se baile es igual a otra. Así, se logra una experiencia de vaciamiento que es instantáneamente llenada por el sentir que propone la música. Esto va sumando componentes que se multiplican en la composición de esta creación comunitaria.

Cuando se baila una cueca, no se puede dejar la pata coja: se debe bailar tres cuecas. Casi se cuenta una historia, con su inicio, desarrollo y final; en cada una de ellas se entrega una versión distinta del mismo sentir: la pareja da vueltas, va y vuelve al centro y a los lados, escobilla y zapatea, siempre mirándose a los ojos. Pareciera ser el ir y venir que las vicisitudes de la vida ponen como obstáculos para encontrarse con el otro, pero que al final del día permite tomar de la mano nuevamente a su otro.

Aquí se otorga, como dijimos, el carácter confesional: en la posibilidad de estar en un espacio comunitario lleno de otros y donde se regala la mirada, que grita desesperada por el encuentro con otra, a una sola persona que acepta en una relación de reciprocidad que cons- 
truye un relato como cualquier otro, pero distinto a todos, con su superestructura y microestructura. En las vueltas se da la posibilidad de expresión de lo propio y de lo común, pero esta vez entre dos. La confesión ahora se realiza con los cuerpos. Es posible establecer, además, relaciones simbólicas entre cada acción de este baile. Los movimientos dicen, comunican y confiesan de la misma forma que las palabras ${ }^{18}$. Es comprensible que, en un espacio cerrado como la ciudad, o más propiamente urbano, la forma de referirse al canto es "pegar el grito", como si se desease manifestar la presencia de los individuos en la vorágine de la ciudad. El entorno construido en su momento para el hombre se ha vuelto en su contra, y es ahora necesario que el hombre escape de él. La planificación ha fallado, las ciudades han estallado en caos y esto se vuelve parte de la identidad de toda una generación que retoma la tradición y la actualiza. Este caos está presente en:

una zona en que la ciudad deja de ser ciudad y el campo deja de ser campo. Opera una relación despresencializadora que, bajo el pretexto de simbiotizar, optimizando ambos términos, los ausenta, convirtiendo el espacio y a su habitante en área de la nadidad (Sepúlveda 45).

Quizás, si realizamos un acercamiento a una imagen en específico, en la que podamos ver esa área de nadidad, no habría nada mejor que hablar de la Vega y el Matadero, espacios en los que, estando en la ciudad, se respira el campo que no llega a ser tal por los límites de su propio contexto espacial, pero que homogeniza aspectos culturales (o más bien formas de vida). Un dicho popular dice "Después de Dios está la Vega”, ubicándola en el punto en donde sucede la vida.

Para Sepúlveda, el folclore deforma la estructura con la que se comprende el arte, cambiando el lugar del arte y el espectador, puesto que el folclor no apunta a la obra como creada, sino como creadora de la subjetividad del espectador que ve su mundo reflejado en ella (75). Lo anterior se aclara entendiéndolo como una "expresión y creación del mundo [que] es expresión y creación del hombre en dialéctica dialógica, vinculante" (68). Este reflejo no está constituido como una foto-

\footnotetext{
${ }_{18}$ Sobre esto, en el documental "La Cueca. Danza de la vida y de la muerte", Margot Loyola muestra cómo, con las posiciones del pañuelo, se puede connotar distintos mensajes.
} 
grafía del entorno del cual se habla, sino como un diálogo con él, generando cambios que modifican constantemente la propia tradición, adaptándola y apropiándola a las variantes de la comunidad.

En este ámbito, la chilena brilla por su capacidad de hablar de lo humano en el humano. Su poesía saca a la luz todo aquello que debía permanecer oculto, que no es más que lo que el hombre guarda en su cotidiano, teniendo por afición principal las relaciones humanas, las parejas, las farras $^{19}$, el campo y la ciudad. Se comprende, entonces, que en su interpretación la relación con el otro cobra sentido en cuanto, si bien es posible que el canto sea entonado por un solo cantor, la forma de la rueda invita a que sea un canto colectivo que en sí mismo contiene la posibilidad de la alteridad: la relación con otro distinto que, en comunión conmigo, crea.

El canto a la rueda es una cosa viviente, tiene cuerpo y alma o sea doble cerradura para lo de afuera y lo de adentro. Es lo cerrado y lo abierto, para después volver a empezar, porque en todo su desciframiento no hay primera sin segunda, y porque el equilibrio no se consigue con una sola parte, sino que el contrario se hace con dos formas diferentes, como es la regla y el compás o la copla y la siguiriya (Claro Valdés et al. 78).

De esta forma, el canto de la chilena se vuelve comunitario, de modo que no pueda ser si no hay lote; sin amistad y comunión con el otro y con el ambiente, no puede ser cantada ni bailada. Así, no puede haber cueca sin identidad, pues es expresión de la tradición que trasciende las costumbres, uniéndolas con la naturaleza y formando un equilibrio entre la alteridad del otro y la individualidad propia.

Esta creación no remite solo a la expresión propia de la musicalidad de la chilena, sino al ambiente, pues la cueca fue hecha para la farra. De sus formas primitivas se dice:

Allí [barriada "Abajo 'el puente"] se observaban las alegrías populares dancísticas desatas a todo vapor, y un halo jocundo de alboroto primitivo envolvía a la abigarrada confluencia de cantores, tañedores, bailarines y espectadores con la magia de la zamacueca crispante (Garrido 24).

Fiestas. 
Este relato habla, propiamente, de las barriadas de la chimba en las que, cuentan los taitas, se establecieron las casas de remolienda, al otro lado del Mapocho, las que, en un análisis superficial de la historia, son las primeras reuniones y fiestas de la rotada, y que declaran el mismo sentir que envuelve a la chilena que hoy conocemos. Los taitas dicen que la cueca es jolgorio que, en tanto elemento simbólico y estético, es el bullicio reflejo de la urbanidad en la que se inserta la chilena, que se suma al alcohol ${ }^{20}$, la fiesta y el grito para sacar al hombre de su común estar. La alteración de la percepción del entorno libera de lo mutilante que tiene el cotidiano, aniquilando a su vez la anestesia que este supone para la conciencia, volviendo a las personas a la mera contemplación de la hermosa niña morena que baila con su historia, en el centro de un círculo donde se canta la vida.

Esta capacidad de alterar la conciencia inserta a la persona en la diacronía propia del folclore que, nuevamente, se ajena del "arte de autor conocido", recalcando su imposibilidad de encasillarlo en un tiempo y espacio determinados, volviéndose crónica actualizada del pasado y el ahora, y recuperando la memoria sin temor a llegar a ser solo pasado, porque incluso en lo futuro podrá actualizarse. Su actualización recae en que su expresión sea propia de lo humano, "es a lo largo del tiempo que se va configurando el texto, definiendo la invariante que determina la relación sintagma-paradigma" (Sepúlveda 72). En la chilena, pareciera que el paradigma siempre será lo humano que habita sus espacios, y su sintagma, sus expresiones que siempre refieren al anterior. Estos elementos configurados poco a poco por el tiempo en sentido histórico se asientan en la rueda creando un ambiente: la farra chilenera.

La farra, la fiesta chilena, puede ser vista bajo las consideraciones de Gadamer (1998), quien propuso la fiesta como aquello que "nos une a todos" (117), haciéndonos parte de un espacio y tiempo propios de nuestras condiciones culturales, convirtiendo la fiesta en la obra que mejor retrata nuestro modo de habitar.

$20 \quad$ "Psicológicamente, está inmersa en un sentido lúdico ajeno a las languideces peculiares de culturas exógenas, cuales las de trasuntos islámicos-arábigos que tienden a crear estados de embriaguez emotiva introvertida" (Garrido 14). 
En este ambiente que se convierte en arte, por ser expresión propia de las personas que lo habitan y celebran, siendo creadores y expresión de lo que allí acontece y confluye, lo que allí acontece no es más que la unión de sus vidas, afectadas por los entornos que las han formado bailando, cantando, bebiendo, celebrando el compartir su cultura. Todas estas relaciones logran, precisamente, ser expresión plena en la farra chilenera.

\section{El ambiente de la chilena: la farra}

Luego de haber hecho algunas aproximaciones al estudio de la chile$n a$ en cuanto experiencia estética, constituida en un ambiente que actualiza una forma interpretativa diacrónica, que implica al individuo como forma de arte en un contexto que en sí es expresión del acontecer cotidiano, podemos determinar que la cueca tiene la posibilidad de ser estudiada como experiencia estética desde variadas perspectivas.

La cueca puede ser abordada como lírica popular, en cuanto es poesía con base en la tradición oral de los bajos fondos de la urbe y del campo chileno. Como expresión musical, por su dimensión sonora, necesaria para su transmisión y para lo que nació: ser cantada. Como baile, elemento confesional que, en cuanto tal, es relevante de ser estudiado, y, por último, como experiencia estética, como ambiente, en tanto confluencia de las tres otras formas de acercamiento al estudio estético de la chilena.

Entender la chilena como ambiente abriría las puertas a una nueva forma de entender el estudio estético ya realizado sobre ella, pudiendo comprender en conjunto sus actores, el canto, la forma de vida y el espacio en el que se enmarca, y el resto de las aristas que confluyen en la expresión de la hermosa niña morena. De esta forma, es posible ampliar la vista y entender no tan solo la lírica, el canto y el baile, sino que también la farra como aquel espacio en que confluyen entre sí estos elementos, seduciendo la conciencia del roto y acercándolo a su identidad, resignificando su chilenidad no como un nacionalismo circense, sino siendo chileno a la chilena.

No se debe entender al roto que habita este ambiente en su mera individualidad, porque en esta expresión el individuo pasa a ser un elemento del ambiente, no negando su humanidad, sino que en con- 
ciencia de que pasa a ser parte de lo otro, que está en comunión con él, en sintonía con su expresión.

Para comprender lo anterior, se debe volver a la relación semántica del canto a la rueda, en la que se encuentra la imposibilidad de la expresión sin el otro, que hace que el canto se vitalice. Esta relación es semántica porque en el entorno urbano, en donde el otro no tiene consistencia por su ser-otro, en la unión por el canto y la farra, toma importancia tanto en lo mío como en lo otro, que se conjugan para que la hermosa niña morena cobre vida. Vida que no es mía ni del otro, sino del ambiente en el que se habita.

En esta construcción se resignifica al otro como parte del ambiente que yo habito y que habita en mí. Por tanto, la alteridad propia de lo otro se significa en cuanto forma parte de mí. Esta relación desborda la común relación con el otro en la urbanidad, que impone su velocidad y caos y constituye, a partir de la experiencia estética de la chilena, un orden ético en las relaciones interpersonales. Las relaciones que se construyen en la rueda no son tan solo de creación, sino de real amistad con otro que se interesa por la realidad de quien crea con él, sin perder lo guapo ${ }^{21}$, cantor y habiloso, pues esa realidad en la que él se inserta es la misma que la suya, con la que interpretan su arte. Además, el ambiente es de fiesta, se reúnen a celebrar, lo que siempre es con otro. Así, el ambiente deja de ser ajeno, al albergar y construir relaciones filiales.

Es importante no entender el ambiente de la cueca como una fotografía a la farra, que ha de ser estudiada y vista desde afuera, sino que para realizar este estudio estético es necesario adentrarse en ella y ver el movimiento de quienes la habitan, invitándola a bailar una pata y confesarle lo que se está sintiendo con ella en tres vueltas con remate. Esto es, ponerse en movimiento.

En efecto, el ambiente, siendo fruto de la chilena, es capaz de hacer confluir los acontecimientos de la vida del roto, actualizando su memoria, haciendo resurgir las tradiciones de los taitas. De esta forma, el ambiente es dinámico y no puede ser encerrado entre cuatro paredes, en un libro o en cualquier otro intento de aprehensión; como toda ex-

Sujeto bravo, dispuesto a pelear, en la jerga cuequera. 
periencia, solo puede ser vivida. Quizá, estas conclusiones le dan razón a Sepúlveda y a su tesis de Arte-Vida, pero, sobre todo, invitan a quien pretenda aproximarse a esta experiencia a hacerse parte de una forma de manifestación artística que desborda los estudios académicos e introduce al espectador en la obra, haciéndolo parte de ella como creador y, en definitiva, lo ponen en movimiento e invitan al estado orgiástico de la fiesta chilena.

Como se puede sentir, hablar de la chilena es bailarse una pata y pegarse el grito, rememorar, hacer vida la tradición, observar e involucrarse, pero sobre todo dejarse afectar por esta emocionalidad inmanente a la historia de lo chileno, puramente chileno, con el sufrimiento y la alegría propia del bajo pueblo, del roto, que canta para ser oído por los suyos, con lenguajes que son comprensibles por quienes están al margen. Hablar de la chilena es testimoniar una forma de arte que ha sido oculta en la marginalidad por un pueblo que vela por ella. No podemos quedarnos quietos en campos disciplinares, debemos ir al encuentro y dar la vuelta cuando cambia el cantor para intentar abarcarla, sabiendo que antes de poder lograrlo se va a acabar, hay que rematar.

\section{Consideraciones finales sobre las experiencias estéticas folclóricas, la fiesta y la filosofía como fiesta}

En definitiva, experiencias estéticas como esta son las que han de estudiarse en los tiempos que corren, ya que tienen la capacidad de cuidar las pasiones de sus actores, atienden a los temas que les importan y mantienen vivas las memorias de los pueblos. El folclor verdaderamente aferrado a sus raíces es una fuente de sabiduría que permite vislumbrar la historia de los que no pueden contarla y cantarla, bailarla, compartirla y celebrarla.

La chilena logra que sus composiciones alberguen los problemas de su tiempo: así como algunas hablan de la precariedad laboral del Matadero Franklin, hoy asoman aquellas que poetizan las circunstancias de Chile, la historia de la mujer y las violaciones a los derechos humanos, demostrando que la poesía popular tiene más fuerza que nunca al momento de expresar lo que padecen los pueblos. 
Si comprendemos las tradiciones como ambientes festivos antes que como repeticiones de costumbres pasadas, podremos entender la complejidad y el dinamismo de estas expresiones. La chilena no se ha quedado quieta desde su desconocido nacimiento, sino que ha cambiado junto con los chilenos y chilenas; ha captado las motivaciones de sus cultores y ha aceptado los cambios, como si absorbiese lo que sucede en el país. En esto último reside lo relevante para los estudiantes de filosofía, y en especial para aquellos que se interesen por la estética.

Los textos, las obras plásticas, la tradición filosófica, en general, no son muestra de una tradición anecúmene, de un tiempo pasado, sino que se actualizan constantemente al hacerse de alguien que les otorgue algún sentido al encontrarse con ellos. Son espacios y tiempos, ambientes que hacen bailar y cantar, que dan arte a la vida, haciendo de ella un arte. Así como la farra invita al juego, imposibilitando la detención de sus actores, moviéndose ella misma y mutando en conjunto con chilenos y chilenas, la tradición filosófica también puede ser entendida como una fiesta, con sus movimientos, tiempos y cantos a lo que fuere su objeto de reflexión. ¿Por qué no hacer de la filosofía una fiesta, un espacio donde incorporar lo gregario, donde mirar a los ojos, conversar y conversarnos, bailarnos, cantarnos, jugarnos?

La filosofía como fiesta supone reflexionar respecto de temas como estos, acerca de cosas a las que se dedican aquellos sobre los que no se ha reflexionado lo suficiente, esto es, pensar - pero también sentir- lo que le sucede al roto, a los marginados, a las personas, derribando las barreras de lo otro. Y esto no tan solo atendiendo a ellos como a objetos de la filosofía, porque si la filosofía es fiesta, los celebrantes son quienes hacen la fiesta para ellos mismos. Quizás sea el momento no de "dar voz a los pueblos", sino de hacer que se eleven las voces que siempre han estado ahí y no han sido escuchadas, dejar que peguen el grito y escucharlos, entendiendo que la fiesta es lo que nos une a todos.

Debemos recordar, antes de rematar, que la cueca no puede hablarse en buen castellano y como la cosa es con cueca, no se podría cerrar un estudio de la chilena a la chilena sin una: 


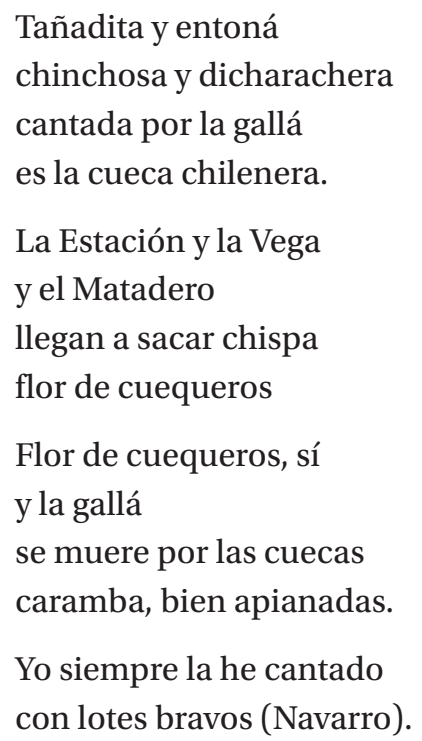

\section{Bibliografía}

Castillo, L. A punta e' palma la cueca [Grabado por L. Tricolores]. De Cuecas de Remolienda [CD]. Santiago, Chile, 2003. Recuperado el 28 de Abril de 2019, de http://cancionerodecuecas. fonotecanacional.cl/\#!/disco/108.

Castro, Luis. Por la Güeya del Matadero, Memorias de la Cueca Centrina. Santiago, Chile: Autoedición, 2011.

Claro Valdés, S. Chilena. Santiago de Chile: Editorial Universitaria, 1994.

Enciclopedia Herder. Enciclopedia Herder: una gran base de conocimiento. (H. Editorial, Editor), s/f. Recuperado el 8 de Mayo de 2019, de https://encyclopaedia.herdereditorial.com/ wiki/Est\%C3\%A9tica

Espinosa, C. S. ¡Pego el grito en cualquier parte! Historia, tradición y performance de la cueca urbana en Santiago de Chile durante el periodo postdictatorial (1990-2010). Madrid: Universidad Complutense de Madrid, 2015.

Gadamer, H-G. El juego como hilo conductor de la explicación ontológica (8a ed.). Salamanca: Ediciones Sígueme, 1999.

Gadamer, H-G. La actualidad de lo bello: El arte como juego, símbolo y fiesta. España: Ediciones Paidós Ibérica, S.A., 1998. 
Garrido, P. Historial de la Cueca Chilena. Valparaíso: Ediciones Universitarias de Valparaíso de la Universidad Católica de Valparaíso, 1979.

Giannini, H. "Interloquio II, El Bar". La "Reflexión" Cotidiana, hacia una arqueología de la experiencia. Humberto Giannini. Santiago, Chile: Editorial Universitaria, 1995. 88-94.

Música Popular. "Los Chileneros" La enciclopedia de la música chilena. Web. 29 de abril de 2019. <http://www.musicapopular. $\mathrm{cl} /$ grupo/los-chileneros/>

Navarro, C. Cancionero Discográfico de Cuecas Chilenas. (EMI Odeon), 1973. Recuperado de http://cancionerodecuecas.fonotecanacional.cl/\#!/disco/54

Rojas, M. (Dirección). La Bitácora de Los Chileneros [Película], 1998.

Sepúlveda, F. Arte Vida. Santiago, Chile: Liberalia Ediciones, 2015.

Torres, S. F. Cancionero de la Cueca Chilena (3a ed.). Santiago, Chile: Tajamar Editores, 2008. 